\title{
Clinical Reasoning: A 71-Year-Old Man With Horizontal Gaze Palsy, Anarthria, and Quadriparesis
}

Ikreet Cheema, MD, Nicole Ng, MD, and Tychicus Chen, MD, FRCPC

Neurology ${ }^{\circledR} 2021 ; 96: 1146-1150$. doi:10.1212/WNL.0000000000012048

\section{Section 1}

A 71-year-old right-handed male nonsmoker with type 2 diabetes, hypertension, and chronic lymphocytic leukemia (CLL) never requiring active treatment presented to the hospital with 1 week of subacute-onset nausea, vomiting, and unsteady gait. On examination, he was afebrile with blood pressure $155 / 82 \mathrm{~mm} \mathrm{Hg}$ and heart rate $62 \mathrm{bpm}$. He had right hemiataxia with widebased gait. CT head and CT angiogram resulted in ischemic stroke diagnosis with no vascular abnormalities. Cardiac workup was unremarkable. He was managed with antiplatelet therapy and risk factor optimization.

Following discharge, the patient's symptoms worsened, with intractable nausea, hyperemesis, weight loss, slurred speech, and loss of independent ambulation, resulting in hospital readmission 2 weeks later. Repeat imaging showed mild lesion expansion. Despite receiving antiplatelets, he progressively deteriorated, becoming nonverbal, communicating with gestures, and eventually becoming seemingly nonresponsive with no movement beyond eye opening. $\mathrm{He}$ required intubation, subsequent tracheostomy, and transfer to our center for further evaluation 3 months into his presentation.

At this point, the patient remained afebrile and normotensive without meningismus. He was nonverbal with spontaneous eye opening and blinking. He could look up and down to written commands with preserved vertical saccades and tracking, but no horizontal eye movements. Pupillary and corneal reflexes were preserved with impaired cough. He had spasticity with no spontaneous limb movements or resistance to strength testing. Painful stimulation caused upper extremity extensor posturing and triple flexion in the lower extremities. Deep tendon reflexes were brisk with bilateral extensor plantar responses.

On further history, we learned that the patient was born in India, emigrating to Canada 40 years ago. He had no preceding infectious or constitutional symptoms, recent travel, previous tuberculosis, or sick contacts.

\section{Question for Consideration:}

1. What is the expected localization of the patient's deficits on initial presentation and subsequently following transfer?

\author{
Correspondence \\ Dr. Cheema: \\ ikreet.cheema@ \\ alumni.ubc.ca
}

\section{MORE ONLINE}

(C) Infographic

http://links.lww.com/WNL/ B411

GO TO SECTION 2

From the Division of Neurology, Faculty of Medicine, University of British Columbia, Vancouver, Canada.

Go to Neurology.org/N for full disclosures. Funding information and disclosures deemed relevant by the authors, if any, are provided at the end of the article. 


\section{Section 2}

Initial presentation with right-sided appendicular and gait ataxia is consistent with ipsilateral cerebellar hemispheric lesion seen on CT. Following worsening cerebellar symptoms, there was new hypodensity in the right middle cerebellar peduncle (figure 1A).

Subsequent neurologic deterioration with retained alertness, anarthria, horizontal gaze palsy, and spastic quadriparesis suggests lesion extension into the brainstem, particularly the ventral pons, and is clinically consistent with a locked-in syndrome. Decerebrate posturing suggests lower brainstem involvement. Lesions of the basis pontis involving bilateral corticospinal and corticobulbar tracts lead to quadriparesis, upper motor neuron signs, and oropharyngeal and facial paralysis. Horizontal gaze palsy with spared blinking and vertical eye movements is a result of selective pontine circuit involvement including the cranial nerve VI nuclei and paramedian pontine reticular formation but sparing of vertical eye control in the rostral midbrain. Preserved consciousness is secondary to reticular formation sparing. MRI brain revealed abnormal T2/fluid-attenuated inversion recovery signal in the middle cerebellar peduncles extending into the cerebellum, pons, and pontomedullary junction (figure 1B).

\section{Question for Consideration:}

1. Given the patient's clinical progression and neuroimaging, what is the differential diagnosis at this point?

\section{GO TO SECTION 3}

Figure 1 Serial Neuroimaging With CT and MRI Demonstrating Lesion Progression

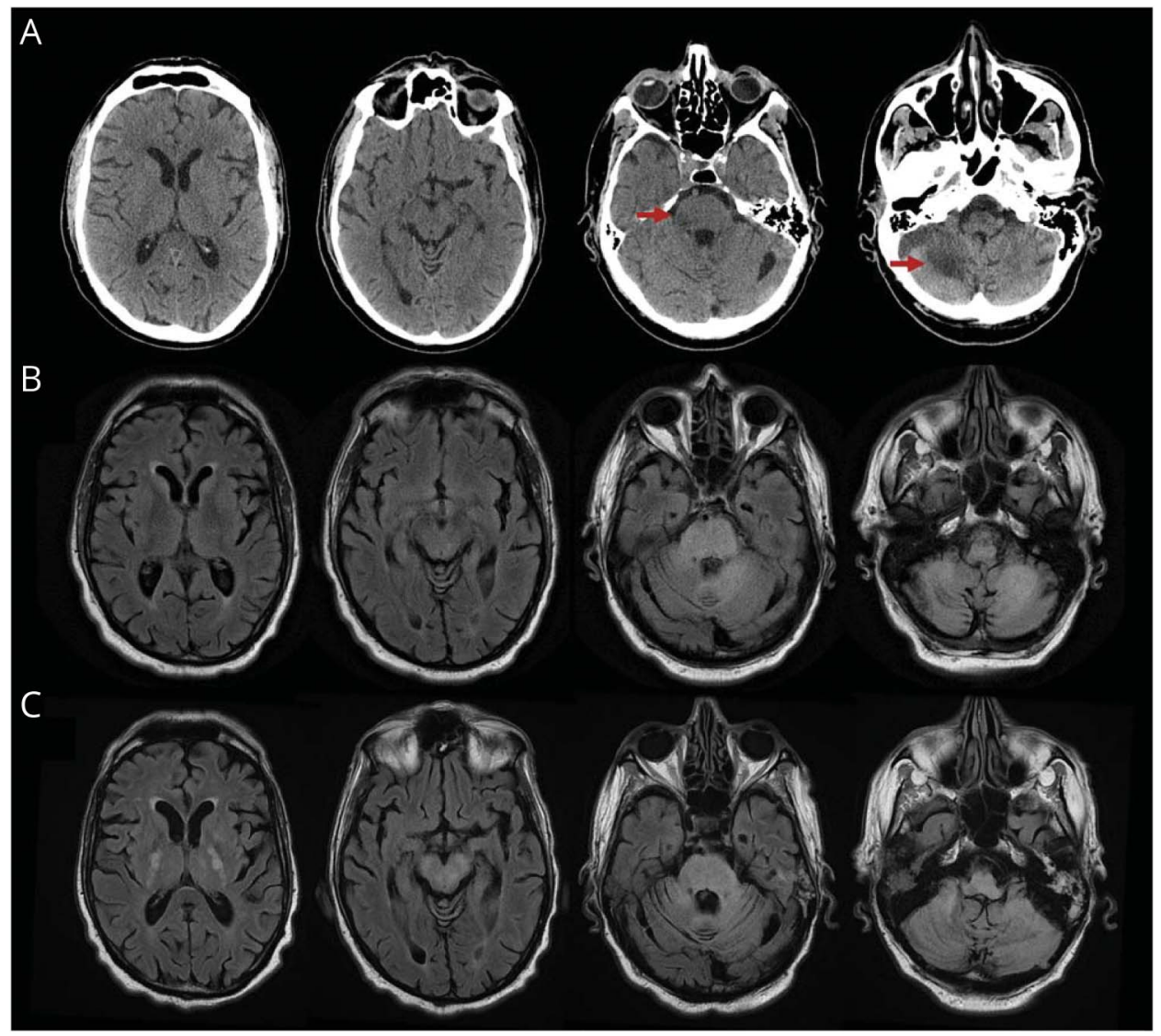

(A) Noncontrast axial CT head reveals right cerebellar hemisphere hypodensity with involvement of the right middle cerebellar peduncle (see arrows) and no supratentorial abnormalities. (B) Axial MRI T2/fluid-attenuated inversion recovery performed 1 month after the CT head demonstrates extensive abnormal hyperintensity in the right and left middle cerebellar peduncles extending into the cerebellum, pons, and pontomedullary junction. There was additional presence of restricted diffusion and no contrast enhancement in these areas (not shown). (C) Repeat MRI 2 months later demonstrates extension of hyperintensity into the midbrain and posterior limbs of the internal capsules in addition to increased subcortical white matter foci. 


\section{Section 3}

Gradual clinical and radiologic progression is not in keeping with initial diagnosis of acute stroke and this progressive brainstem involvement is more suggestive of an infectious, inflammatory, malignant, or toxic/metabolic process.

Rhombencephalitis refers to inflammation of the rhombencephalon, comprising the pons, medulla, and cerebellum. ${ }^{1}$ There are numerous causes including infectious, autoimmune, and paraneoplastic etiologies. ${ }^{1-3}$ Among infectious causes, the most prevalent are Listeria, enterovirus 71, and the herpesviruses, including herpes simplex virus (HSV), Epstein-Barr virus (EBV), human herpesvirus type 6, and less commonly, cytomegalovirus (CMV) and varicella-zoster virus (VZV). ${ }^{1}$ Flaviviruses, particularly the mosquito-borne Japanese encephalitis virus endemic to Asia, are also associated, although this patient had no travel history. Progressive multifocal leukoencephalopathy (PML) is caused by John Cunningham virus (JCV) reactivation, typically in immunosuppressed individuals, and can cause infratentorial lesions. ${ }^{2}$ This patient was never treated with immunosuppressants for his stable CLL, but CLL itself may disrupt innate and adaptive immunity. ${ }^{4}$ Rare bacterial causes include Mycobacterium tuberculosis, Brucella, Borrelia, Salmonella, Legionella, and Mycoplasma. Given gastrointestinal symptoms, Tropheryma whipplei was considered, as reported in one case of rhombencephalitis in a patient with rheumatoid arthritis on methotrexate. 5

Neuro-Behçet disease is the most common autoimmune cause; however, this patient does not fit the typical age and demographic, with no systemic symptoms including mucocutaneous ulcerations, uveitis, or rash. $^{1}$ Cases have also been reported in systemic lupus erythematosus and relapsing chondritis. ${ }^{1}$ Primary CNS vasculitis may also be considered as it can affect any part of the CNS, although not specific to the rhombencephalon. This was deemed unlikely as the patient's symptoms are gradually progressive with expansion of the primary lesion and absence of enhancement, hemorrhage, and vascular abnormalities such as arterial beading. Demyelinating disorders such as multiple sclerosis (MS), neuromyelitis optica, and acute disseminated encephalomyelitis were similarly considered unlikely given age and demographic characteristics. Neurosarcoidosis is another inflammatory disease with diverse manifestations. ${ }^{3}$ Bickerstaff brainstem encephalitis is a consideration given symptoms of ataxia and ophthalmoparesis, although there was no antecedent infection. ${ }^{3}$ CLIPPERS (chronic lymphocytic inflammation with pontine perivascular enhancement responsive to steroids) is an inflammatory syndrome of the brainstem, particularly the pons, which classically presents radiologically with punctate enhancement, not seen in this patient.

Paraneoplastic causes are typically associated with anti-Yo and anti-Tr antibodies secondary to gynecologic and breast cancer as well as anti-Hu, anti-Ri, anti-Ma, and anti-amphiphysin antibodies, often from underlying small cell lung cancer. ${ }^{1}$ This patient was a lifelong nonsmoker.

In addition to rhombencephalitis, neoplastic etiologies such as lymphoma or a brainstem glioma are diagnostic possibilities given the patient's older age and immunosuppression.

Toxic/metabolic causes with this appearance that may be considered include the brainstem variant of posterior reversible encephalopathy syndrome given CLL history, but the patient was never on immunosuppressive medications and his blood pressure was not significantly elevated at presentation. Finally, although clinical history is not suggestive, osmotic demyelination syndrome resulting from rapid sodium correction typically presents with central pontine T2 hyperintensity and restricted diffusion.

\section{Questions for Consideration:}

1. What investigations will you order?

2. What treatments will you initiate?

GO TO SECTION 4 


\section{Section 4}

The patient's peripheral lymphocyte count was stable. Serum protein electrophoresis, rheumatologic panel, and inflammatory markers were unremarkable. Broad-spectrum antimicrobials including acyclovir and ampicillin (for Listeria coverage) were initiated until lumbar puncture revealed unremarkable cell count $\left(1 \times 10^{6} / \mathrm{L}\right.$ leukocytes, $4 \times 10^{6} / \mathrm{L}$ erythrocytes), $339 \mathrm{mg} / \mathrm{L}$ protein, and negative culture. Subsequent MRI brain with contrast revealed no enhancement. Lumbar puncture was repeated following transfer, also unremarkable with normal cytology and JCV testing ordered. CSF PCR was negative for HSV, VZV, and enterovirus. Serologies for HIV, CMV, EBV, VZV, Brucella, Bartonella, Histoplasma, and Cryptococcus were all negative. Interferon-gamma release assay was negative for tuberculosis. Paraneoplastic antibodies, angiotensin-converting enzyme, and oligoclonal bands were negative with normal immunoglobulin $\mathrm{G}$ synthesis rate.

The patient was then treated with pulse steroids, IV immunoglobulins, and plasma exchange (PLEX) therapy without improvement. CT chest, abdomen, pelvis and testicular ultrasound were unremarkable. Duodenal biopsy was negative for Whipple disease. Brain biopsy was deemed unfeasible given location. EEG showed diffuse encephalopathy. Ultimately, CSF JCV DNA was detected at high titer and rhombencephalitis secondary to PML was diagnosed.

Mirtazapine was initiated. The patient continued to decline clinically and radiologically despite supportive care. Repeat MRI showed lesion extension into the midbrain as well as bilateral posterior internal capsules and subcortical white matter involvement (figure 1C). He ultimately died of respiratory failure 4 months after initial presentation.

Autopsy revealed widespread PML corresponding to abnormal MRI posterior fossa regions and microscopic lesions in frontal and parieto-occipital subcortical white matter (figure 2). Death was attributed to PML with CLL a contributory risk factor.

\section{Discussion}

PML was first recognized in CLL and Hodgkin lymphoma in $1958 .^{6,7}$ Following the 1980 s AIDS epidemic, $80 \%$ of cases were seen in patients with HIV/AIDS, with $13 \%$ in hematologic malignancies. ${ }^{7}$ In the mid-2000s, a second wave of PML was observed with new therapeutic monoclonal antibodies, namely natalizumab in the treatment of MS and other immunosuppressants for autoimmune conditions and organ transplant. PML is rare in patients with stable CLL under surveillance who have never received treatment, with 1 report in the literature. ${ }^{8}$

\section{Figure 2 Histopathology of Progressive Multifocal Leukoencephalopathy}

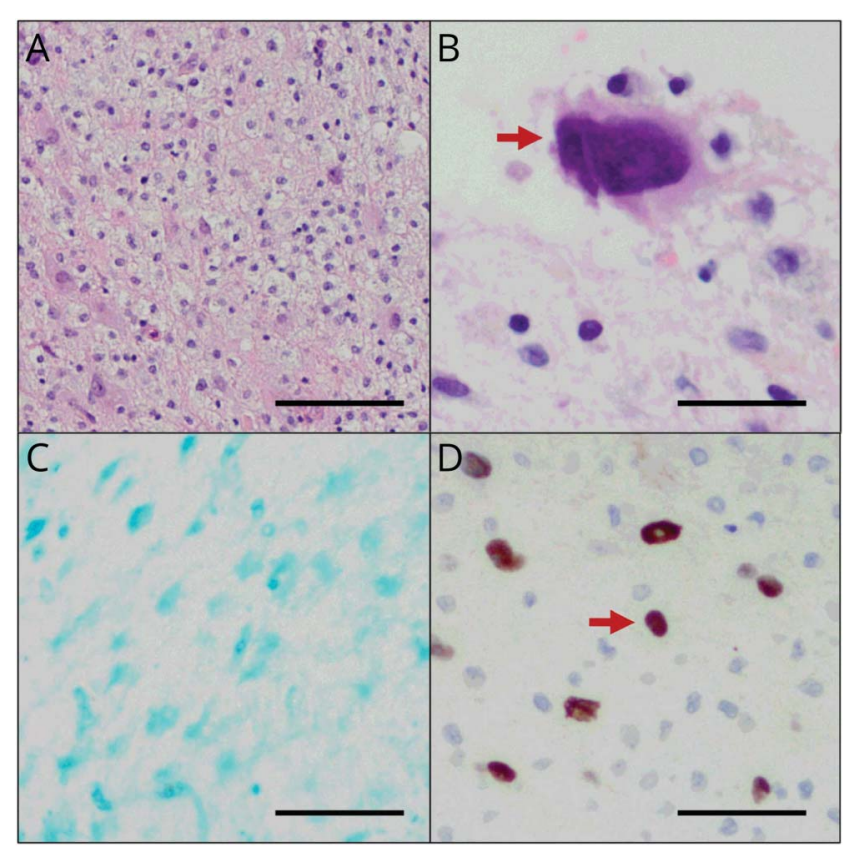

(A) Hypercellularity with macrophagic infiltration of white matter (confirmed macrophagic by CD68 immunohistochemical staining; not shown). (B) Astrocyte with bizarre-shaped, enlarged nucleus (arrow). (C) Demyelination revealed by Luxol fast blue staining. (D) Strongly positive SV40 immunohistochemical staining indicative of active polyomavirus replication in glial cells (arrow). Scale bars: $100 \mu \mathrm{m}(\mathrm{A}), 50 \mu \mathrm{m}(\mathrm{B}-\mathrm{D})$.

JCV is a double-stranded DNA virus of the polyomavirus family widespread among mostly asymptomatic individuals with seroprevalence between $33 \%$ and $90 \%{ }^{6}$ After initial infection, it becomes dormant in tissues including the kidneys, bone marrow, and possibly CNS. ${ }^{6}$ Mechanisms of viral reactivation are not entirely understood but immune system dysfunction is the common underlying factor in predisposing conditions; thus, intact immune functioning is presumed to keep the virus dormant and prevent disease expression. ${ }^{7}$ When activated, infected oligodendrocytes become enlarged with prominent intranuclear inclusion bodies and lysis, resulting in myelin loss. ${ }^{6}$

The clinical presentation of PML is diverse, with subacute focal or multifocal neurologic deficits that can initially be mistaken for stroke. ${ }^{6}$ Symptoms and signs depend on area of CNS involvement. There is a single previous report of PML presenting as locked-in syndrome in a patient treated with rituximab for relapsed follicular lymphoma and this manifestation seems to be rare. ${ }^{9}$ Seizures have been reported in $20 \%$ of patients. ${ }^{7}$ PML should be considered in immunosuppressed patients presenting with subacute progressive neurologic symptoms. CSF PCR for JCV DNA is preferred for minimally invasive diagnosis, with reported sensitivity ranging from $74 \%$ to $92 \%$ and specificity from $92 \%$ to $100 \%$, although 
pathologic examination is definitive. ${ }^{6} \mathrm{MRI}$ is sensitive in showing typically bilateral, diffuse, confluent T2-hyperintense white matter lesions, although single lesions can occur. ${ }^{7}$ Commonly there is subcortical involvement of the parietooccipital and frontal lobes, the corpus callosum, pyramidal tracts, and the posterior fossa, particularly the middle cerebellar peduncles with cerebellar or pontine extension as in this case. ${ }^{6,7}$ Lesions tend to be nonenhancing with presence of diffusion restriction. ${ }^{7}$

There is no direct anti-JCV therapy. Numerous agents have been studied with limited evidence and are not considered effective treatment, including antiviral agents such as mirtazapine, cytarabine, cidofovir, and mefloquine, as well as immune response modulators such as interferon- $\alpha$, interleukin-2, and most recently, immune checkpoint inhibitors. ${ }^{10,11}$ Outcomes depend on recovering immune system function or immune reconstitution. If applicable, immunosuppressive therapy withdrawal and antiretroviral therapy optimization in patients with HIV are key treatment aspects. PLEX has been used in patients with MS with PML secondary to natalizumab for peripheral drug clearance. ${ }^{10}$ PML remains incurable, with high mortality within the first 3 months of diagnosis and worse prognosis portended by higher CSF viral load and involvement of crucial CNS areas such as the brainstem. ${ }^{6}$

\section{Study Funding}

No targeted funding reported.

\section{Disclosure}

The authors report no disclosures relevant to the manuscript. Go to Neurology.org/N for full disclosures.

\begin{tabular}{|c|c|c|}
\hline Name & Location & Contribution \\
\hline $\begin{array}{l}\text { Ikreet } \\
\text { Cheema, } \\
\text { MD }\end{array}$ & $\begin{array}{l}\text { University of British } \\
\text { Columbia, Vancouver, } \\
\text { Canada }\end{array}$ & $\begin{array}{l}\text { Study design, drafted the } \\
\text { manuscript, revised manuscript } \\
\text { for intellectual content }\end{array}$ \\
\hline $\begin{array}{l}\text { Nicole Ng, } \\
\text { MD }\end{array}$ & $\begin{array}{l}\text { University of British } \\
\text { Columbia, Vancouver, } \\
\text { Canada }\end{array}$ & $\begin{array}{l}\text { Revised manuscript for } \\
\text { intellectual content, pathology } \\
\text { acquisition and interpretation }\end{array}$ \\
\hline $\begin{array}{l}\text { Tychicus } \\
\text { Chen, MD, } \\
\text { FRCPC }\end{array}$ & $\begin{array}{l}\text { University of British } \\
\text { Columbia, Vancouver, } \\
\text { Canada }\end{array}$ & $\begin{array}{l}\text { Supervision, study conception } \\
\text { and design, revised manuscript } \\
\text { for intellectual content }\end{array}$ \\
\hline
\end{tabular}

\section{References}

1. Jubelt B, Mihai C, Li TM, Veerapaneni P. Rhombencephalitis/brainstem encephalitis. Curr Neurol Neurosci Rep. 2011;11(6):543-552.

2. Moragas M, Martínez-Yélamos S, Majós C, Fernández-Viladrich P, Rubio F, Arbizu T. Rhombencephalitis: a series of 97 patients. Medicine. 2011;90(4):256-261.

3. Tan IL, Mowry EM, Steele SU, et al. Brainstem encephalitis: etiologies, treatment, and predictors of outcome. J Neurol. 2013;260(9):2312-2319.

4. Arruga F, Gyau BB, Iannello A, Vitale N, Vaisitti T, Deaglio S. Immune response dysfunction in chronic lymphocytic leukemia: dissecting molecular mechanisms and microenvironmental conditions. Int J Mol Sci. 2020;21(5):1825.

5. Balducci C, Foresti S, Ciervo A, et al. Primary Whipple disease of the central nervous system presenting with rhombencephalitis. Int J Infect Dis. 2019;88:149-151.

6. Sahraian MA, Radue E-W, Eshaghi A, Besliu S, Minagar A. Progressive multifocal leukoencephalopathy: a review of the neuroimaging features and differential diagnosis progressive multifocal leukoencephalopathy. Eur J Neurol. 2012;19(8):1060-1069.

7. Bag AK, Curé JK, Chapman PR, Roberson GH, Shah R. JC virus infection of the brain. Am J Neuroradiol. 2010;31(9):1564-1576.

8. Neil EC, DeAngelis LM. Progressive multifocal leukoencephalopathy and hematologic malignancies: a single cancer center retrospective review. Blood Adv. 2017;1(23): 2041-2045

9. Hopfinger G, Plessl A, Grisold W, et al. Progressive multifocal leukoencephalopathy after rituximab in a patient with relapsed follicular lymphoma and low IgG levels and a low CD4+ lymphocyte count. Leuk Lymphoma. 2008;49(12):2367-2369.

10. Pavlovic D, Patera AC, Nyberg F, Gerber M, Liu M. Progressive multifocal leukoencephalopathy: current treatment options and future perspectives. Ther $A d v$ Neurol Disord. 2015;8(6):255-273.

11. Koralnik IJ. Can immune checkpoint inhibitors keep JC Virus in check? N Engl J Med. 2019;380(17):1667-1668.

\section{Disputes \& Debates: Rapid Online Correspondence}

The editors encourage comments on recent articles through Disputes \& Debates:

Access an article at Neurology.org/ $N$ and click on "MAKE COMMENT" beneath the article header.

Before submitting a comment to Disputes \& Debates, remember the following:

- Disputes \& Debates is restricted to comments about articles published in Neurology within 6 months of issue date

- Read previously posted comments; redundant comments will not be posted

- Your submission must be 200 words or less and have a maximum of 5 references; the first reference must be the article on which you are commenting

- You can include a maximum of 5 authors (including yourself) 


\section{Neurology}

Clinical Reasoning: A 71-Year-Old Man With Horizontal Gaze Palsy, Anarthria, and Quadriparesis

Ikreet Cheema, Nicole $\mathrm{Ng}$ and Tychicus Chen

Neurology 2021;96;1146-1150 Published Online before print April 14, 2021

DOI 10.1212/WNL.0000000000012048

This information is current as of April 14, 2021

\section{Updated Information \&}

Services

References

Permissions \& Licensing

Reprints including high resolution figures, can be found at:

http://n.neurology.org/content/96/24/1146.full

This article cites 11 articles, 2 of which you can access for free at: http://n.neurology.org/content/96/24/1146.full\#ref-list-1

Information about reproducing this article in parts (figures,tables) or in its entirety can be found online at:

http://www.neurology.org/about/about_the_journal\#permissions

Information about ordering reprints can be found online:

http://n.neurology.org/subscribers/advertise

Neurology ${ }^{\circledR}$ is the official journal of the American Academy of Neurology. Published continuously since 1951, it is now a weekly with 48 issues per year. Copyright (C) 2021 American Academy of Neurology. All rights reserved. Print ISSN:

0028-3878. Online ISSN: 1526-632X

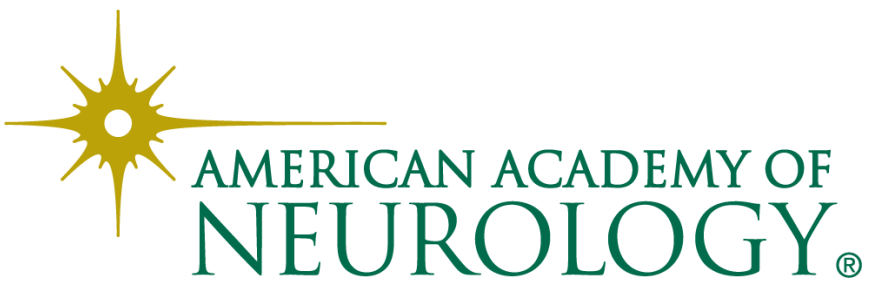

